\title{
EPISTOLARY STYLE AS AN OBJECT OF A LINGUOCULTUROLOGICAL RESEARCH
}

\author{
Inna A. Koroleva \\ Smolensk State University, Smolensk, Russia
}

\begin{abstract}
The article highlights some peculiarities of epistolary colloquial speech, registered in a businessand-friendly written dialogue of the Russian creative intelligentsia in the late $20^{\text {th }}$ century. The material for this scientific consideration were some letters of A.V. Makedonov, a Smolensk-born literary historian, critic and publicist addressed to Yu. V. Pashkov, a Smolensk poet, whose literary talent A.V. Makedonov always wished to support; the letters, which have never been under study, are available at Smolensk University Literary Museum Archive.

A complex analysis of the epistolary style in the letters by A.V. Makedonov was based on the communicativeand-pragmatic and linguoculturological approaches and directed at reconstruction of a speech portrait with regard to the several levels of speech personality, in particular, the semantic level, which characterizes the epistolary style as a written form of colloquial speech, the linguo-cognitive level, that singles out epistolary concepts conductive to informational and assessment aspects of the letters, and the motivation level, which implies analysis of speech acts and speech-etiquette standards in the letters, makes it possible to single out several peculiarities of the communicants' inter-relations on a par with their personal characteristics.

In conclusion the article sums up epistolary stylistic peculiarities of A.V. Makedonov's creative personality and speech culture.

Key words: epistolary style, epistolary idiostyle, epistolary etiquette, A.V. Makedonov, Yu.V. Pashkov, colloquial speech, language personality, speech culture.

Citation. Koroleva I.A. Epistolary Style as an Object of a Linguoculturological Research. Vestnik Volgogradskogo gosudarstvennogo universiteta. Seriya 2. Yazykoznanie [Science Journal of Volgograd State University. Linguistics], 2019, vol. 18, no. 2, pp. 174-182. (in Russian). DOI: https://doi.org/10.15688/jvolsu2.2019.2.15
\end{abstract}

УДК 81:008:82-6

ББК 81.006 .3
Дата поступления статьи: 21.01.2019

Дата принятия статьи: 03.04.2019

\section{ЭПИСТОЛЯРНЫЙ СТИЛЬ КАК ОБЬЕКТ ЛИНГВОКУЛЬТУРОЛОГИЧЕСКОГО ИССЛЕДОВАНИЯ}

\author{
Инна Александровна Королёва \\ Смоленский государственный университет, г. Смоленск, Россия
}

\begin{abstract}
Аннотация. В статье рассматриваются особенности эпистолярной разговорной речи творческой российской интеллигенции второй половины XX в., проявляющиеся в деловом и дружеском письменном диалоге. Материалом для исследования послужили письма известного советского историка литературы, критика и публициста А.В. Македонова, смолянина по рождению, к смоленскому поэту Ю.В. Пашкову, которому он оказывал постоянную поддержку на литературном поприще. Письма хранятся в архиве Литературного музея Смоленского государственного университета и впервые вводятся в научный оборот. Проведено комплексное изучение речевого материала в русле коммуникативно-прагматического и лингвокультурологического подходов и в соответствии с уровнями исследования речевой личности и реконструкции речевого портрета говорящего: на семантическом уровне охарактеризован эпистолярный стиль как письменная форма разговорной речи; на лингвокогнитивном уровне выделены эпистолярные концепты, позволяющие анализировать информативную и оценочную стороны эпистолярия; на мотивационном уровне посредством анализа (0) содержащихся в письмах речевых актов и стандартов речевого этикета показаны особенности взаимоотно-
\end{abstract}


шений коммуникантов, выявлены некоторые черты их личности. Делается вывод об особенностях эпистолярного стиля творческой языковой личности А.В. Македонова, о его речевой культуре.

Ключевые слова: эпистолярный стиль, эпистолярный идиостиль, эпистолярный этикет, А.В. Македонов, Ю.В. Пашков, разговорная речь, языковая личность, речевая культура.

Цитирование. Королёва И. А. Эпистолярный стиль как объект лингвокультурологического исследования // Вестник Волгоградского государственного университета. Серия 2, Языкознание. - 2019. - Т. 18, № 2. C. 174-182.-DOI: https://doi.org/10.15688/jvolsu2.2019.2.15

\section{Введение}

Коммуникативная стилистика - одно из перспективных научных направлений исследований, в котором важное место занимает исследование эпистолярных текстов как особых способов коммуникации. Специфика эпистолярия обусловлена тем, что он представляет собой письменную форму речевого общения, имеющего дистанционный характер, на которую существенное влияние оказывают личностные характеристики адресанта и адресата, характер их взаимоотношений, темы коммуникации, затекстовые ситуации и т. д. и которая позволяет хранить информацию в устойчивой неизменяемой форме частного письма.

Эпистолярные тексты занимают промежуточное положение между художественными и документальными. Поэтому при публикации частных писем перед издателями всегда встает вопрос о возможности / невозможности по этическим, моральным и иным соображениям «придать огласке» заключенную в них информацию.

В настоящее время существует разнобой в терминологическом определении статуса эпистолярия. В зависимости от направленности исследования лингвисты используют термины «эпистолярный жанр», «эпистолярный стиль», «эпистолярный дискурс», «эпистолярная литература» (см., например: [Бетузия, 1984; Кожеко, 2015; Козлова, Кушнина, 2012; Курьянович, 2008; Фесенко, 2008; Цыцарина, 1989]. Мы считаем, что в коммуникативной стилистике текста предпочтительнее использовать термин «эпистолярный стиль», который в справочной литературе трактуется как исторически сложившаяся разновидность письменной речи, в которой используется форма писем или посланий (эпистол) (греческое epistole «послание, письмо») [Кохтев, 1998, c. 639; Протопопова, 2003, с. 631]. Поскольку письмо является единицей эпистолярной ком- муникации, ему присущи все признаки речевого жанра [Кирьянова, 2007a, с. 125-126; 20076 , с. 246]. Как считает М. Бахтин, речевой жанр характеризуется с точки зрения коммуникативной ситуации, экспрессии, объема, концепции адресата и нададресата [1986, c. 458,496$]$.

В обмене эпистолами участвуют две стороны - адресант и адресат, и именно характеристики коммуникантов (возраст, пол, социальное положение, степень знакомства, их личные отношения, индивидуальные речевые особенности) во многом определяют языковую специфику текстов. При коммуникативном подходе к изучению эпистолярия важно оценивать мотивы обмена письмами, цель и задачи эпистолярной коммуникации, ситуации написания отдельных посланий и проч. Интенсивную переписку, как правило, мотивирует общность профессиональной среды, дружеского круга, бытовых дел и т. д.

На основании анализа различных точек зрения и исследований эпистолярия Н.И. Белунова в качестве основных характеристик письма выделяет следующие: эксплицитная направленность на адресата; реализация коммуникативно-прагматической оси «Я - Ты»; политематичность; полифункциональность; отражение особенностей речевого этикета; смысловая завершенность; структурное единство, специфика которого обозначается наличием границ (начало и конец письма), являющихся своего рода формализаторами; прикрепленность к определенной ситуации; целостность образа содержания, поддержанного двумя слоями информации: эксплицитно выраженной и имплицитной, контекстной; система коммуникативных задач, отражающих особенности языковой личности адресанта и адресата; индивидуально-авторская манера письма [Белунова, 2000, с. 75-78].

Традиционно изучению подвергаются письма известных деятелей политики, куль- 
туры, а переписка выдающихся личностей становится фактом литературного наследия. Речевая практика людей, связанных с литературным творчеством, - это своеобразный синтез элементов литературного языка с возможными вкраплениями просторечной и даже диалектной лексики. На эту особенность частных писем обратила внимание О.Н. Седова [Седова, 1985, с. 57]. Некоторые лингвисты отождествляют язык эпистолярия с литературной разговорной речью, однако, как справедливо отмечает И.А. Лешутина, «любой письменный памятник несет на себе отпечаток литературности, особенно когда речь идет о “почтовой прозе” писателей и поэтов. В этом случае... уместнее говорить об своеобразной эпистолярной разговорной речи» [Лешутина 2003, с. 35]. Это убеждение разделяет Т.П. Акимова, утверждая, что именно эпистолярные тексты мастеров слова отражают правильную разговорную речь той или иной исторической эпохи [Акимова, 2016, с. 5, 8; и др.]. Заметим, что помимо этого в письмах имеет место своеобразие индивидуально-авторского эпистолярного идиостиля, позволяющего воссоздать черты языковой личности коммуникантов и реконструировать их речевые портреты, а следовательно охарактеризовать отношения коммуникантов, их личностные особенности и тем самым показать значимость личности пишущего в литературном контексте эпохи. В связи с этим целесообразной при изучении эпистолярия представляется интеграция коммуникативного и лингвокультурологического подходов.

Наиболее исследованы в лингвистике письма классиков отечественной словесности, хранящиеся в центральных архивах и музеях, тогда как письма видных деятелей российской и советской культуры из фондов региональных архивов и музеев редко становились объектом лингвистического описания. Эту лакуну отчасти восполняет исследование, результаты которого представлены в статье.

\section{Характеристика объекта исследования}

Объектом нашего исследования являются письма Адриана Владимировича Македонова (1909-1994) - известного советского критика, публициста и историка литературы, смо- лянина по рождению, литератора, много лет сотрудничавшего со смоленскими мастерами слова, - к известному смоленскому поэту, члену Союза писателей России, краеведу Юрию Васильевичу Пашкову (1930-2017). Письма хранятся в архиве Литературного музея Смоленского государственного университета (фонд № 7, единица хранения № 2, с. 42-60). Всего 11 писем. 7 из них напечатаны на пишущей машинке, 4 написаны от руки, но во всех есть личная подпись А.В. Македонова. Судя по архивным листам, эти письма еще не были объектом научного исследования.

В литературном мире имя Македонова прочно связано со Смоленщиной. Именно он в 1960 г. выделил Смоленскую поэтическую школу и назвал ее основоположников: М.В. Исаковского, А.Т. Твардовского и Н.И. Рыленкова. С тех пор деятельность поэтов Смоленского края рассматривалась как особое направление в контексте русской (советской) поэзии. К представителям этой школы можно отнести и Пашкова, который хорошо известен не только смоленским, но и российским читателям [Смоленская область..., 2001, c. 153-154, 189].

\section{Результаты и обсуждение}

Исследование писем А.В. Македонова выполнено нами в русле коммуникативнопрагматического и лингвокультурологического подходов с использованием традиционных для них методов и приемов.

Каждое из 11 писем начинается с этикетных формул приветствия. Отметим, что во всех письмах Македонов обращается к Пашкову только Дорогой Юрий Васильевич, что, на наш взгляд, свидетельствует, с одной стороны, о дружеских отношениях, с другой - об определенной дистанции в коммуникации. Эта дистанция поддерживается употреблением только местоимения $B b l$, хотя у коммуникантов достаточно большая разница в возрасте Пашков младше, он «ученик», но «учитель» никогда не пишет ему $m b l$.

Стандартной является и этикетная формула подписи: Ваш А.M. Македонов (в 6 письмах), Ваш А. Македонов (в 3 письмах), Ваш A.M. (в 2 письмах); она неизменно сопровождается подписью от руки. В 10 письмах из 
11 подписи предшествует этикетная формула привета, который Македонов передает знакомым смолянам, что свидетельствует о его постоянном желании «соприкасаться» с родным Смоленском и его жителями: Привет всем смолянам (18 мая 1974); Привет землякам (26 декабря 1975); Привет землякам (25 января 1977); Привет всем знакомым (9 апреля 1982); Привет всем землякам (1 марта 1983) и др.

О желании автора писем узнавать новости литературного Смоленска свидетельствуют и этикетные вопросы в концовках некоторых писем: Как дела всей смоленской писательской организачии и литературной средыl? (26 июля 1982); Кто же Вам в Смоленске помог в трудную минуту? Хочется и об этом знать, ибо все, касающееся Смоленщины, и даже окололитературных нравов для меня, как стойкого смоляка, всегда интересно (22 декабря 1982); Каково Bаше мнение о стихах Мишина? О Мишине в иелом? Как движется дело о приеме в ССП Раисы Ипатовой? Как здоровье Нины Семеновой? (1 марта 1983); Как прошла годовщина Рыленкова? Что еще нового в Смоленской и Вашей личной литературной жизни? (28 ноября 1984).

Постоянная «смоленская линия» в письмах Македонова показывает его тесные связи с родным городом. В одном из первых писем находим: $B$ будущем году хочется и коечто написать о новых успехах наших смоляков... но еще думаю над формой этого (26 декабря 1975). В письмах упоминается большое количество имен смоленских литераторов, с ними Македонов, судя по текстам, был либо знаком лично, либо хорошо знал их творчество. Критик часто спрашивает мнение Пашкова о стихах молодых смолян: Р. Ипатовой, Н. Егоровой, о сборнике стихов В. Смирнова, о пьесах Н. Семеновой и т. д. О некоторых пишет неоднократно и дает оценку творчеству: Поэтесса безусловно талантливая, и это радует. Еще один ярус смоленской поросли вырос (о Р. Ипатовой, 9 апреля 1982). Вот оценка некоторых смолян только из одного письма (26 июля 1982): Человек, кстати сказать, очень достойный и образованный, который может многим помочь смоленским литераторам (о В. Баевском); Сме- лость, как известно, берет города и на Парнасе, а она пишет все смелей и смелей»; «...интересны пьесы молодого врача 3. Кагана» (о Н. Семеновой). Таким образом, в письмах эксплицируется лингвокультурный концепт «Смоленск», что свидетельствует о тесной духовной связи Македонова со своей малой родиной. Его интересует даже частный вопрос о том, как правильнее называть жителей Смоленщины: Как, кстати, по Вашему мнению, все-таки лучше говорить - смоляки? Смоленцы? Смоляне? (25 сентября 1978). Сам Македонов чаще употребляет устаревшее ныне смоляки (общеупотребительное - смоляне).

Хорошо известно о давних дружеских и литературных связях А.В. Македонова и А.Т. Твардовского, которого критик считал центральной фигурой выделенной им в 1960 г. Смоленской поэтической школы. В письмах Македонова к Пашкову реализуется концепт «Семья Твардовских». Тема семьи Твардовского интересовала Македонова на протяжении всей его деятельности, и он пытался через окружение поэта понять его «феномен».

По мнению Македонова, писать о Твардовском - долг, и этот долг еще не отдан. Критик постоянно упоминает о своей книге о Твардовском, которую писал в конце 70-х гг. ХХ в.: Дела еще очень переполняют. И главный долг - по отношению к А.Т. - еще далек от выполнения (26 декабря 1975); Mы с P.A. (жена Македонова, Раиса Абрамовна. И. К.) собираемся побывать в Смоленске в этом году - я пару недель должен кое-что еще посмотреть для своей книги об А.T. (25 января 1977). Как видим, Македонов делится с Пашковым своими творческими и издательскими планами, что свидетельствует о доверительных профессиональных отношениях коммуникантов.

Приведем отрывок письма Македонова с оценкой семьи Твардовских, который считаем образцом эпистолярного идиостиля Македонова: Что касается семейных дел Твардовских, то здесь ситуация сложная и не однозначная. Вся эта семья интересна не только сопричастием судьбе великого поэта, но и собственными личностями, во многом незаурядными, и всей своей историей, как бы сконцентрировавщей на тес- 


\section{МАТЕРИАЛЫ И СООБЩЕНИЯ}

ной человеческой площчадке типичные $и$ вместе с тем экстремальные судьбы миллионов людей в течение большого отрезка намей истории. И самое расслоение, и даже антагонизм внутри этой семьи очень показательны. Не только как показатель среды Твардовского. Тем более что по крайней мере двое из братьев - Константин и Иван - люди несомненно яркие, очень одаренные, очень много и сложно пережившие, и при всех своих различиях это настоящие таланты труда и необыкновенной жизненной энергии. Люди, которые, перефразируя известные слова Твардовского, все превзошли и с поля труда и жизни не ушли (22 ноября 1982).

К судьбе семьи Твардовских Македонов обращается и в других письмах, используя разнообразные оценочные лексемы: Семья... противоречивая, многострадальная в иелом все же достойная уважения и серьезного изучения не только биографами Твардовского, но и биографами времени, семья (23 ноября 1983). Типичным для стиля Македонова является выражение оценки посредством прилагательных, однако не менее точны и существительные, причем автор писем не боится «называть вещи своими именами», то есть давать и отрицательную оценку: брат Павел - пьяница, алкоголик (23 ноября 1983).

Реализация центрального концепта эпистолярия - «Творчество» - связана с оценкой стихов Ю.В. Пашкова. Критик практически в каждом письме характеризует произведения поэта, проводит подробный анализ отдельных стихотворений и сборников стихов. Уже в первом письме мы читаем: ...Пишу Вам о $\mathrm{Ba}$ шей книге. Я ее сразу же прочитал, и она сразу же мне понравилась (за исключением некоторых стихотворений)... Главное впечатление - книга хорочая. Много настоящих стихов. Вы - поэт. ...Много великолепных миниатюр... есть много хороших мест... искреннее поэтическое чувство... у Вас есть свой голос, свой путь... Прекрасные места в стихах... хорошие строчки (18 мая 1974). Речь идет о первом сборнике стихов, изданном в Москве, - «Соколья гора» (1974). Высказывая критические замечания, Македонов не обижает поэта-земляка, а старается по-доброму научить его. С некоторой иронией дает самооценку: Я придирчив, как старый критикан и блохоискатель. Блохи, недотяжки в сборнике, мелкие огрехи. Но все это, конечно, мелочи (18 мая 1974).

В последующих письмах отражено дружеское участие Македонова в судьбе Пашкова: Македонов пишет рецензии на его сборники, анализирует отдельные стихи в тексте писем, дает советы. Выработан уже эпистолярный стиль оценки: частотными являются прилагательные, выражающие положительную оценку: поэтическая смелость, органическое чувство земли, углубленная духовность, смелые и точные метафоры-ассоииации (Македонов первым отметил эту особенность стихотворной манеры Пашкова. И. K.). Однако отмечены и прилагательные в метафорическом употреблении, выражающие отрицательную оценку (критические замечания): недоношенные определения-слова, ходячие литературные представления (25 января 1977).

О постоянном интересе Македонова к творчеству Пашкова свидетельствуют этикетные фразы, выражающие эмоциональное состояние адресанта: Рад был увидеть в «Литературной России» хотя бы небольшую, но вполне положительную рецензию на Вашу последнюю книгу (25 сентября 1978); На днях я с удовольствием прочитал вполне положительную рецензию на Вашу книгу в «Литературном обозрении». Она сходится и с моей оиенкой, о которой я Вам писал. Важно, что книга получила признание в иентральной печати (1 марта 1983); Буду рад прочесть новые Ваши стихи (23 июня 1983); Всегда рад читать Ваши новые стихи (23 декабря 1983); Всегда рад получать от Вас письма и новые стихи (28 ноября 1984) и т. п. Македонов видел в Пашкове достойного представителя Смоленской поэтической школы, что выражается разнообразными эпистолярными речевыми актами: утверждение - Важно, что Вы уже завоевали среди смоляков тот минимум признания, без которого бывает трудно двигаться дальше (25 января 1977); пожелание - Хотелось бы, чтобы и Выл лично, и другие продолжатели, наследники основателей Смоленской... иколы, немножко меньше избегали... рисков. Время суровой правды; со- 
вет - Каждый пусть идет своей колеей... (28 ноября 1984).

Переписка, судя по частотной реализации этического речевого акта «Благодарность», была полезна для обоих коммуникантов и отражает их крепкие дружеские отношения: Спасибо за присланную рецензию (26 декабря 1976); Спасибо за отзыв на мое сочинение и за Ваши новые стихи (25 января 1977); Вы писали, что могли бы мне прислать последние публикации смоленских писателей. Буду благодарен (1 марта 1983); Благодарю за заметку о моем юбилее, за добрые слова и пожелания Рад буду, если эти пожелания в какой-то мере оправдаю (30 мая 1984).

Переписка была регулярной, но все же с некоторыми перерывами, о чем свидетельствуют этикетные фразы извинения: Давно от Вас нет известий. Мне казалось, что я когда-то отвечал на Ваше последнее письмо, но может быть и ошибаюсь. Все же прошу прощения за задержку (25 сентября 1978); K стыду своему обнаружил, что, кажется, до сих пор не ответил на Ваше апрельское письмо. Это не было подражанием Вашему долгому молчанию, а просто как-то так получилось... Прошу за это прощения (26 июля 1982). В целом в рассматриваемые годы переписка была продуктивной.

Характер отношений между коммуникантами проявляется и в реализации речевого акта эпистолярного стиля «Поздравление»отношения между Македоновым и Пашковым не близкие, а дружеско-деловые: Будьте здоровы. Р.А. и я еше раз поздравляем с Новым Годом, желаем здоровья, всех благ и прежде всего мук и радостей созидания новой книги (26 декабря 1976); Поздравляю с Новым Годом, будьте здоровы, счастливы (22 декабря 1983). Возможно, это не все сохранившиеся письма и поздравительных речевых актов было больше.

В качестве черты идиостиля Македонова можно отметить ограниченное употребление разговорных слов. Они использованы ситуативно, для более яркого описания состояния адресанта: ....Муторно от всех тех же фонтанов болтологии (при рассказе о неформальных разговорах с неприятными для него людьми, 26 декабря 1975); ...Заболел, ухитрился простудиться, навалились срочные дела по службе, немного очухался (о своей задержке ответа на письмо Пашкова, 18 мая 1974); предстоит пыхтеть и пыхтеть (о ситуации трудной работы над книгой о Твардовском, 30 мая 1984). В контекстах, имеющих иное тематическое наполнение, разговорные слова представлены единичными вкраплениями (письмишко, жилка, недоделка, незавершенка и проч.). Такая черта идиостиля Македонова, как употребление большого количества этикетных эпистолярных книжных оборотов, свидетельствует об интеллигентности Македонова в общении с людьми, с которыми он поддерживает дружески-творческие отношения, не переходящие в тесную дружбу.

\section{Выводы}

Введенные в научный оборот эпистолярные тексты дают возможность выявить специфику эпистолярного идиостиля известного советского критика и публициста, определить черты его языковой личности. Несомненно, А.В. Македонов - элитарная творческая языковая личность, он прекрасно владеет письменной разговорной речью, что характеризует его как высокообразованного интеллигентного человека.

Хорошее владение эпистолярным этикетом позволяет Македонову поддерживать дружеско-деловые отношения с адресатом. Об этом свидетельствуют и многочисленные реализации этикетных речевых актов (извинение, благодарность, поздравление и др.).

А.В. Македонов предстает в эпистолярии (через экспликацию концептов «Семья Твардовских», «Творчество», через ситуативную оценку стихов Ю.В. Пашкова) как высокопрофессиональный историк литературы и литературный критик. Некоторые фрагменты писем можно рассматривать как критические мини-статьи по анализу литературных произведений. При этом оценка (положительная и отрицательная), как правило, выражается посредством прилагательных, часто в метафорическом употреблении. Ограничено использование Македоновым стилистически сниженных лексических единиц. Они являются своеобразными маркерами фрагментов определенного содержания. 


\section{МАТЕРИАЛЫ И СООБЩЕНИЯ}

Анализ эпистолярия показал, что А.В. Македонов, смолянин по рождению, не забывает свою малую родину и постоянно старается быть в курсе дел смоленской творческой интеллигенции. Хотя главной фигурой для Македонова-критика был А.Т. Твардовский (об этом свидетельствует реализация в письмах соответствующего концепта), Ю.В. Пашков стал для него своеобразным символом творчества «новой поросли смоленских поэтов», продолживших традиции А.Т. Твардовского.

\section{СПИСОК ЛИТЕРАТУРЫ}

Акимова Т. П., 2016. Эпистолярный текст: лингвокультурологические характеристики (на материале писем классиков русской литературы XIX-XX вв.). Волгоград : ИП Поликарпов И.Л. $332 \mathrm{c.}$

Бахтин М. М., 1986. Проблема речевых жанров // Литературно-критические статьи. М. : Художественная литература. С. 428-472.

Белунова Н. И., 2000. Дружеское письмо в функционально-стилистическом аспекте // Русский язык в школе. № 1. С. 75-78.

Бетузия Н., 1984. Особенности текстов эпистолярного жанра // Русский язык за рубежом. № 3. C. 81-84.

Кирьянова А. П., 2007а. Адресант в аспекте языковой оценки (на материале писем М.И. Цветаевой) // Известия Российского государственного педагогического университета им. А.И. Герцена. Аспирантские тетради. T. 16, № 40. С. 124-129.

Кирьянова А. П., 2007б. Адресант в виртуальном пространстве письма (на материале эпистолярия М.И. Цветаевой) // Житниковские чтения (VIII; 2007). Информационные системы: гуманитарная парадигма : материалы Всерос. науч. конф. (г. Челябинск, 20-22 февр. 2007 г.) / отв. ред. И. Ю. Голованова. Челябинск : Челябинский государственный университет, 2007. С. 244-249.

Кожеко А. В., 2015. Эпистолярные жанры: традиционные и современные формы // Современные проблемы науки и образования. № 2, ч. 3. URL: https://science-education.ru/pdf/2015/2-3/ 194.pdf (дата обращения: 21.12.2018).

Козлова О. Д., Кушнина Л. В., 2012. Эго-текст в культурно-речевом пространстве // Современные проблемы науки и образования. № 4. URL: https://science-education.ru/pdf/2012/4/ 296.pdf.

Кохтев Н. Н., 1998. Эпистолярный стиль // Русский язык : энциклопедия / гл. ред. Ю. Н. Караулов. 2-е изд., перераб и доп. М. : Большая Рос. энцикл. : Дрофа. С. 639-640.

Курьянович А. В., 2008. Электронное письмо как функционально-стилевая разновидность эпистолярного жанра в пространстве современной коммуникации // Вестник Томского государственного педагогического университета. № 2. C. 4449 .

Лешутина И. А., 2003. Русская разговорная речь (лексика) в «почтовой прозе» первой трети ХІХ столетия. М. : МГОУ. $126 \mathrm{c}$.

Протопопова О. В., 2003. Эпистолярный стиль // Стилистический энциклопедический словарь русского языка / под ред. М. Н. Кожиной. М. : Флинта : Наука. С. 631-634.

Седова О. Н., 1985. Эпистолярный стиль в системе функциональных стилей русского языка // Филологические науки. № 6. С. 57-62.

Смоленская область, 2001. Энциклопедия : в 2 т. / отв. ред. Г. С. Меркин. Т. 1. Смоленск : СГПУ. $303 \mathrm{c}$.

Фесенко О. П., 2008. Эпистолярий: жанр, стиль, дискурс // Вестник Челябинского государственного университета. Серия: Филология. Искусствоведение. № 23 (124). С. 132-143.

Цыцарина О. Ф., 1989. О понятии «эпистолярный жанр» в современной лингвистической литературе // Функционально-семантические аспекты языковых явлений : сб. ст. Куйбышев : Изд-во КГУ. С. 103-110.

\section{ИСТОЧНИК}

Архив Литературного музея СмолГУ, отдел рукописей. Ф. 7. Оп. 1. Ед. хр. 2. С. 42-60.

\section{REFERENCES}

Akimova T.P., 2016. Epistolyarnyy tekst: lingvokulturologicheskie kharakteristiki (na materiale pisem klassikov russkoy literatury $X I X-X X v v$.) [Epistolary Text: Linguoculturological Characteristics (Based on Letters of Russian Literature Classics of the $19^{\text {th }}-20^{\text {th }} \mathrm{c}$.) ]. Volgograd, IP Polikarpov Publ. $332 \mathrm{p}$.

Bakhtin M.M., 1986. Problema rechevykh zhanrov [The Problem of Speech Genres]. Literaturno-kriticheskie statyi [Literary Critical Articles]. Moscow, Khudozhestvennaya literatura Publ., pp. 428-472.

Belunova N.I, 2000. Druzheskoe pismo v funktsionalno-stilisticheskom aspekte [Friendly Letter in the Functional and Stylistic Aspect]. Russkiy yazyk $v$ shkole [Russian Language at School], no. 1, pp. 75-78. 
Betuziya N., 1984. Osobennosti tekstov epistolyarnogo zhanra [Features of Epistolary Genre Texts]. Russkiy yazyk za rubezhom [Russian Language Abroad], no. 3, pp. 81-84.

Kiryanova A.P., 2007a. Adresant v aspekte yazykovoy otsenki (na materiale pisem M.I. Tsvetaevoy) [Addresser in the Aspect of Linguistic Evaluation (By the Material of M. Tsvetaeva's Epistolary Texts)]. Izvestiya Rossiyskogo gosudarstvennogo pedagogicheskogo universiteta im. A.I. Gertsena [Izvestia: Herzen University Journal of Humanities \& Sciences], vol. 16, no. 40, pp. 124-129.

Kiryanova A.P., 2007b. Adresant v virtualnom prostranstve pisma (na materiale epistolyariya M.I. Tsvetaevoy) [Addressee in the Virtual Space of the Letter (Based on the Epistolary of M.I. Tsvetaeva)]. Golovanova I.Yu., ed. Zhitnikovskie chteniya (VIII; 2007). Informatsionnye sistemy: gumanitarnaya paradigma: materialy Vseros. nauch. konf. (g. Chelyabinsk, 20-22 fevr. 2007 g.) [Zhitnikov Readings (8; 2007): Information Systems: Humanitarian Paradigm: Proceedings of the AllRussian Scientific Conference (Chelyabinsk, February20-22, 2007]. Chelyabinsk, Chelyabinskiy gosudarstvennyy universitet, pp. 244-249.

Kozheko A.V., 2015. Epistolyarnye zhanry: traditsionnye i sovremennye formy [Epistolary Genres: Traditional and Modern Forms]. Sovremennye problemy nauki i obrazovaniya [Modern Problems of Science and Education], no. 2, part 3. URL: https://scienceeducation.ru/pdf/2015/2-3/194.pdf (accessed 21 December 2018).

Kozlova O.D., Kushnina L.V., 2012. Ego-tekst v kulturno-rechevom prostranstve [Ego-Text in the Cultural and Discourse Space]. Sovremennye problemy nauki i obrazovaniya [Modern Problems of Science and Education], no. 4. URL: https://science-education.ru/pdf/ 2012/4/296.pdf

Kokhtev N.N., 1998. Epistolyarnyy stil [Epistolary Style]. Karaulov Yu.N., ed. Russkiy yazyk : entsiklopedia [Russian Language: Encyclopedia]. Moscow, Bolshaya Rossiyskaya entsiklopediya, Drofa Publ., pp. 639-640.

Kuryanovich A.V., 2008. Elektronnoe pismo kak funktsionalno-stilevaya raznovidnost epistolyarnogo zhanra $\mathrm{v}$ prostranstve sovremennoy kommunikatsii [E-mail as a Functional and Style Variety of Epistolary Genre in the Field of Contemporary Communication]. Vestnik Tomskogo gosudarstvennogo pedagogicheskogo universiteta [Tomsk State Pedagogical University Bulletin], no. 2, pp. 44-49.

Leshutina, I.A., 2003. Russkaya razgovornaya rech (leksika) v "pochtovoy proze» pervoy treti XIX stoletiya [Russian Colloquial Speech (Lexicon) in the "Postal Prose" of the First Third of the $19^{\text {th }}$ Century]. Moscow, MGOU. $126 \mathrm{p}$.

Protopopova O.V., 2003. Epistolyarnyy stil [Epistolary Style]. Stilisticheskiy entsiklopedicheskiy slovar russkogo yazyka [Stylistic Encyclopedic Dictionary of the Russian Language]. Moscow, Flinta Publ., Nauka Publ., pp. 631-634.

Sedova O.N., 1985. Epistolyarnyy stil v sisteme funktsionalnykh stiley russkogo yazyka [Epistolary Style in the System of Functional Styles of the Russian Language]. Filologicheskie nauki [Philological Sciences], no. 6, pp. 57-62.

Merkin G.S., ed., 2001. Smolenskaya oblast. Entsiklopediya: v 2 t. [Smolensk Region. Encyclopedia. In 2 Vols]. Smolensk, SGPU. 303 p.

Fesenko O.P., 2008. Epistolyariy: zhanr, stil, diskurs [Epistolary: Genre, Style, Discourse]. Vestnik Chelyabinskogo gosudarstvennogo universiteta. Serya: Filologiya. Iskusstvovedeniye [Bulletin of Chelyabinsk State University. Series: Philology. Art Criticism], no. 23 (124), pp. 132-143.

Tsytsarina O.F., 1989. O ponyatii «epistolyarnyy zhanr» v sovremennoy lingvisticheskoy literature [On the Concept of "Epistolary Genre" in Modern Linguistic Literature]. Funktsionalnosemanticheskie aspekty yazykovykh yavleniy: sbornik statey [Functional-Semantic Aspects of Linguistic Phenomena. Collected Articles]. Kuybyshev, Izd-vo KGU, pp. 103-110.

\section{SOURCE}

Arkhiv Literaturnogo muzeya SmolGU, otdel rukopisey [Archive of The Literary Museum of Smolensk State University, Department of Manuscripts]. F. 7. Op. 1. Ed. khr. 2, pp. 42-60. 


\section{МАТЕРИАЛЫ И СООБЩЕНИЯ}

\section{Information about the Author}

Inna A. Koroleva, Doctor of Sciences (Philology), Professor, Department of the Russian Language, Smolensk State University, Przhevalskogo St., 4, 214000 Smolensk, Russia, innakor@mail.ru, https://orcid.org/0000-0002-0597-6921

\section{Информация об авторе}

Инна Александровна Королёва, доктор филологических наук, профессор кафедры русского языка, Смоленский государственный университет, ул. Пржевальского, 4, 214000 г. Смоленск, Россия, innakor@mail.ru, https://orcid.org/0000-0002-0597-6921 